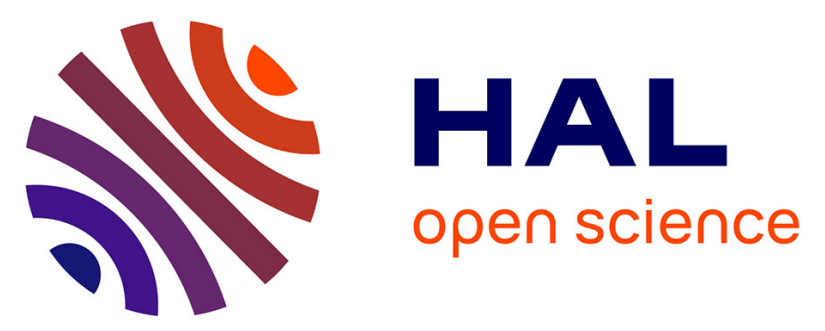

\title{
Nanoscale selective area growth of thick, dense, uniform, In-rich, InGaN nanostructure arrays on GaN/sapphire template
}

Suresh Sundaram, Renaud Puybaret, Xin Li, Youssef El Gmili, Konstantinos Pantzas, G. Orsal, David Troadec, Gilles Patriarche, Paul L Voss, Jean-Paul Salvestrini, et al.

\section{To cite this version:}

Suresh Sundaram, Renaud Puybaret, Xin Li, Youssef El Gmili, Konstantinos Pantzas, et al.. Nanoscale selective area growth of thick, dense, uniform, In-rich, InGaN nanostructure arrays on GaN/sapphire template. Journal of Applied Physics, 2014, 116 (16), pp.163105-163105-6. 10.1063/1.4900531 . hal01077688

\section{HAL Id: hal-01077688 \\ https://hal.science/hal-01077688}

Submitted on 12 Jan 2022

HAL is a multi-disciplinary open access archive for the deposit and dissemination of scientific research documents, whether they are published or not. The documents may come from teaching and research institutions in France or abroad, or from public or private research centers.
L'archive ouverte pluridisciplinaire HAL, est destinée au dépôt et à la diffusion de documents scientifiques de niveau recherche, publiés ou non, émanant des établissements d'enseignement et de recherche français ou étrangers, des laboratoires publics ou privés. 


\title{
Nanoscale selective area growth of thick, dense, uniform, In-rich, InGaN nanostructure arrays on GaN/sapphire template
}

\author{
S. Sundaram, ${ }^{1}$ R. Puybaret, ${ }^{2}$ Y. El Gmili, ${ }^{1}$ X. Li, ${ }^{2}$ P. L. Bonanno, ${ }^{1}$ K. Pantzas, ${ }^{3}$ G. Orsal, ${ }^{4}$ \\ D. Troadec ${ }^{5}$ Z.-H. Cai, ${ }^{6}$ G. Patriarche,${ }^{3}$ P. L. Voss, ${ }^{2}$ J. P. Salvestrini, ${ }^{4, a)}$ and A. Ougazzaden ${ }^{2}$ \\ ${ }^{1}$ CNRS, UMI 2958 Georgia Tech - CNRS, 57070 Metz, France \\ ${ }^{2}$ Georgia Institute of Technology, UMI 2958 Georgia Tech - CNRS, 57070 Metz, France \\ ${ }^{3}$ CNRS, UPR LPN, Route de Nozay, 91460 Marcoussis, France \\ ${ }^{4}$ Université de Lorraine, Supélec, LMOPS, EA4423, 57070 Metz, France \\ ${ }^{5}$ Université des Sciences et Technologies de Lille, CNRS, UMR 8520 IEMN, 59000 Lille, France \\ ${ }^{6}$ Advanced Photon Source, 9700 S. Cass Avenue, Argonne, Illinois 60439, USA
}

(Received 22 July 2014; accepted 15 October 2014; published online 28 October 2014)

\begin{abstract}
Uniform, dense, single-phase, $150 \mathrm{~nm}$ thick indium gallium nitride (InGaN) nanostructure (nanorods and nanostripes) arrays have been obtained on gallium nitride templates, by metal organic chemical vapor deposition and nanoscale selective area growth on silicon dioxide patterned masks. The $150 \mathrm{~nm}$ thick InGaN nanorods have a perfect hexagonal pyramid shape with relatively homogenous indium concentration up to $22 \%$, which is almost twice as high as in planar InGaN grown in the same condition, and luminesce at $535 \mathrm{~nm}$. InGaN nanostripes feature c-axis oriented $\mathrm{InGaN}$ in the core which is covered by InGaN grown along semi-polar facets with higher In content. Transmission electron microscope and sub micron beam X-rays diffraction investigations confirm that both InGaN nanostructures are mostly defect free and monocrystalline. The ability to grow defect-free thick InGaN nanostructures with reduced polarization and high indium incorporation offers a solution to develop high efficiency InGaN-based solar cells. (C) 2014 AIP Publishing LLC.

[http://dx.doi.org/10.1063/1.4900531]
\end{abstract}

\section{INTRODUCTION}

Indium gallium nitride ( $\mathrm{InGaN}$ ) has a tunable direct band gap ranging from $0.64 \mathrm{eV}$ to $3.4 \mathrm{eV}$ and has a high absorption coefficient making it ideal candidate for use in multijunction solar cells. ${ }^{1-5}$ Although InGaN-based light emitting diodes have reached commercial maturity ${ }^{6}$ and InGaN/GaN photovoltaic devices have been recently extensively developed, device performance tends to degrade when In content is high or the InGaN layer thickness increases. ${ }^{7,8}$ This has been attributed to the immiscibility gap of InGaN, ${ }^{9}$ the difficulty of incorporating In under compressive strain, ${ }^{10}$ and the large internal polarization field which significantly hinders carrier collection in $\mathrm{p}-\mathrm{i}-\mathrm{n}$ Ga-face devices. ${ }^{11}$ Thus, planar heteroepitaxy of thick InGaN layers leads to poor morphology and inhomogeneous In content. The use of multi-quantum well architecture on free standing GaN substrates leads also to $\mathrm{V}$-pits which emerge from threading dislocations at the surface of underlying GaN layers and extend to the surface of the InGaN layer. V-pits usually act as nonradiative recombination centers and leakage-current paths in III-nitride thin films, reducing solar cell performance. ${ }^{12}$ It has been shown recently that these issues can be mitigated by periodically turning off the indium precursor flow, to insert thin $\mathrm{GaN}$ interlayers during InGaN growth. ${ }^{13,14}$

Another approach consists in the growth of InGaN nanostructures for the achievement of high In content thick InGaN layers and InGaN/GaN p-i-n solar cells. This approach allows the elimination of the preexisting dislocations in the underlying template. ${ }^{16,17}$ It also allows strain relaxation of $\mathrm{InGaN}$

${ }^{\text {a)} E l e c t r o n i c ~ m a i l: ~ s a l v e s t r @ m e t z . s u p e l e c . f r ~}$ layers, leading to higher In incorporation and reduced piezoelectric effect. Significant work has been reported on InGaN nanostructure fabrication. Among the different fabrication techniques that have been used, selective area growth via patterned substrates enables precise control of the spacing and position of nanofeatures. For instance, Wang et al. ${ }^{18}$ have developed a patterning technique based on a self-organization process, while more recently, Song et al. ${ }^{19}$ have used patterned $\mathrm{SiO}_{2}$ masks on GaN/sapphire templates. Both authors have then used selective area growth into their patterned substrates to obtained InGaN nanostructures.

In this paper, using a specific single step patterning process, we report on the improvement of the results obtained so far in the growth of InGaN nanostructures. Deep structural, morphological, chemical, and optical characterizations clearly demonstrate nanoscale selective area growth (NSAG) using metal organic vapor phase epitaxy (MOVPE) of thick, uniform, dense, single phase, up to $22 \%$ In-content InGaN nanorods arrays, that could be an interesting approach for the development of high efficiency InGaN-based solar cells.

\section{EXPERIMENT DETAILS}

Nano-patterned substrates were fabricated on n-doped $2 \mu \mathrm{m}$ thick c-oriented GaN/sapphire template following a procedure described in Fig. 1. First, a $100 \mathrm{~nm}$ thick negative-tone resist (hydrogen silsesquioxane, HSQ) is spin-coated on the template. The resist is then patterned using an electron-beam lithography system providing a $4 \mathrm{~nm}$ Gaussian beam, that we used at $100 \mathrm{kV}$ accelerating voltage, under a $1.9 \mathrm{nA}$ current. The part of the resist exposed to electron beam cross-links into $\mathrm{SiO}_{2}$. At last, TMAH $25 \%$ etching treatment is used to open 
HSQ

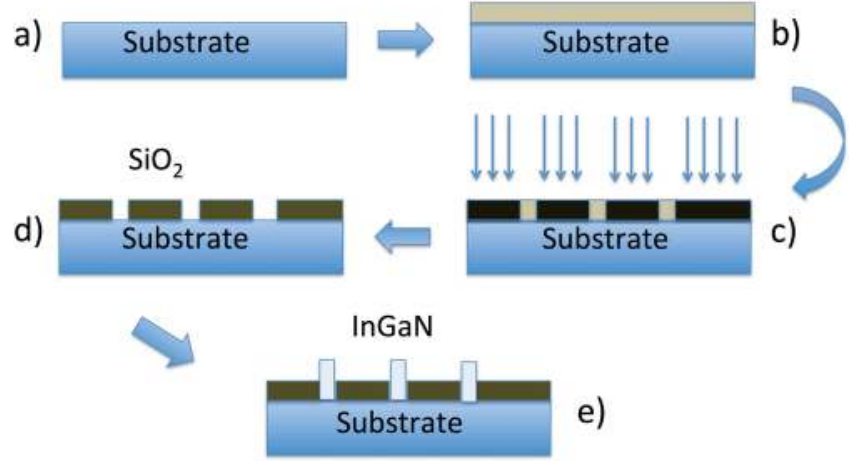

FIG. 1. Scheme of the nano-patterning process used for the growth of InGaN nanostructures: (a) n-GaN/sapphire substrate, (b) HSQ resist spin coating, (c) electron beam lithography allowing cross-link of the resist into $\mathrm{SiO}_{2}$ followed by etching of the unexposed resist, (d) TMAH $25 \%$ etching treatment to open the nano-patterns, and (e) MOVPE InGaN nano selective area growth.

the nano-patterns (nano-holes and nano-stripes). The diameter of the circular opening is $100 \mathrm{~nm}$ and the size of the stripe openings is $10 \times 0.1 \mu \mathrm{m}^{2}$ with an orientation along the (110) direction. This single-step process, compared to the standard deposit-etch method, allows better preservation of the quality of the substrate, first by not exposing the underlying GaN surface to a plasma etch, and then overall by simplifying the process and hence limiting the number of chemicals used on the wafer. Thick InGaN epilayers were then grown on these patterned templates using T-shaped MOVPE reactor. ${ }^{20}$ Trimethyindium (TMIn), trimethylgallium (TMG), and ammonia were used as the precursors for the growth. Growth temperature was $800^{\circ} \mathrm{C}$ under full nitrogen ambient. The structural properties of the InGaN nanostructures were characterized using high-resolution and sub micron beam x-ray diffraction, and transmission electron microscopy (TEM) along the (100) and (110) zone axes. Scanning electron microscope (SEM), cathodoluminescence (CL), and energy-dispersive X-ray spectroscopy mapping (EDX) were employed to assess the morphological properties and In composition of the nanostructures, respectively. After a calibration procedure using GaAs, InP, $\mathrm{GaN}$, AlN, GaP, and GaSb, as well as their ternary alloys (lattice-matched to InP, allowing the composition to be precisely determined through X-ray diffraction (XRD)), quantitative measurements of the indium composition from EDX were obtained from the intensity ratio of the $\mathrm{L} \alpha$ line of indium $(3.290 \mathrm{keV})$ to the $\mathrm{K} \alpha$ line of gallium $(9.770 \mathrm{keV})$. The $\mathrm{K}$ line of elementary nitrogen $(0.392 \mathrm{keV})$ was also taken into account and revealed that the InGaN alloy is stoichiometric. The acquisition time for each EDX spectrum was $60 \mathrm{~s}$, during which no drift in the position of the electron beam was observed. The error in the In composition determination is estimated to $\pm 1 \%{ }^{21}$

\section{RESULTS AND DISCUSSION}

\section{A. Structural and morphological characterizations}

Fig. 2 shows SEM images of perfectly selective InGaN nanostructures grown on circular and stripe openings in the

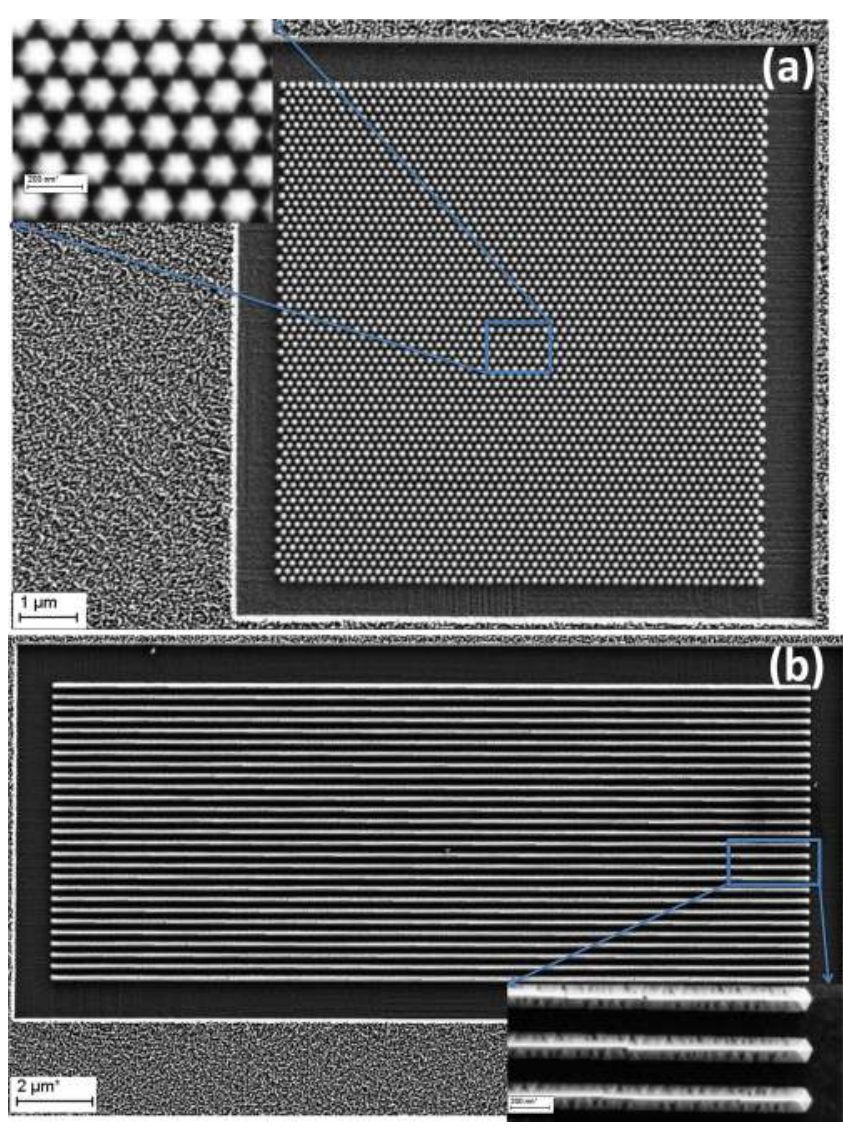

FIG. 2. SEM images of perfectly selective thick InGaN nanostructure arrays grown on GaN templates in (a) circular opening and (b) stripe opening.

patterned substrate, respectively. As a result of optimized growth conditions, InGaN growth on the patterned area is perfectively selective, without any polycrystalline deposits on the masks. The pattern with circular openings contains InGaN nanorods which have a hexagonal pyramid shape. More than 3000 consecutive nanorods have been grown without any defect or polycrystalline deposits. It is clear that InGaN nanostripes show an elongated hexagonal pyramid shape. InGaN nanostructures exhibit well defined shape and size uniformity, exposing the six (1-102) triangular r-plane facets. The InGaN nanorods have smooth facets whereas nanostripes show irregular triangular $r$-plane facet formation on the two elongated sidewalls. The other four small triangular planes are smooth as observed in the nanorods. This indicates that there is competition between InGaN growing in different orientations, which has different growth rates, and In incorporations. Even though there is some inhomogeneity in the sidewall morphology of InGaN stripes, both nanostructures are smooth which means that a 3D stress relief mechanism is in place. This mechanism mitigates straininduced degradation, usually present in planar InGaN, which induces inclusions, V-pits, trench pits, In clustering, and 3D growth as shown either in the unmasked area of the sample or control sample grown along with the patterned sample as revealed by the SEM image in the inset of Fig. 3. This figure shows also the measured high-resolution XRD $2 \theta-\omega$ scan and a simulated fit for the (002) reflection plane of the control sample grown along with the patterned sample. From the 


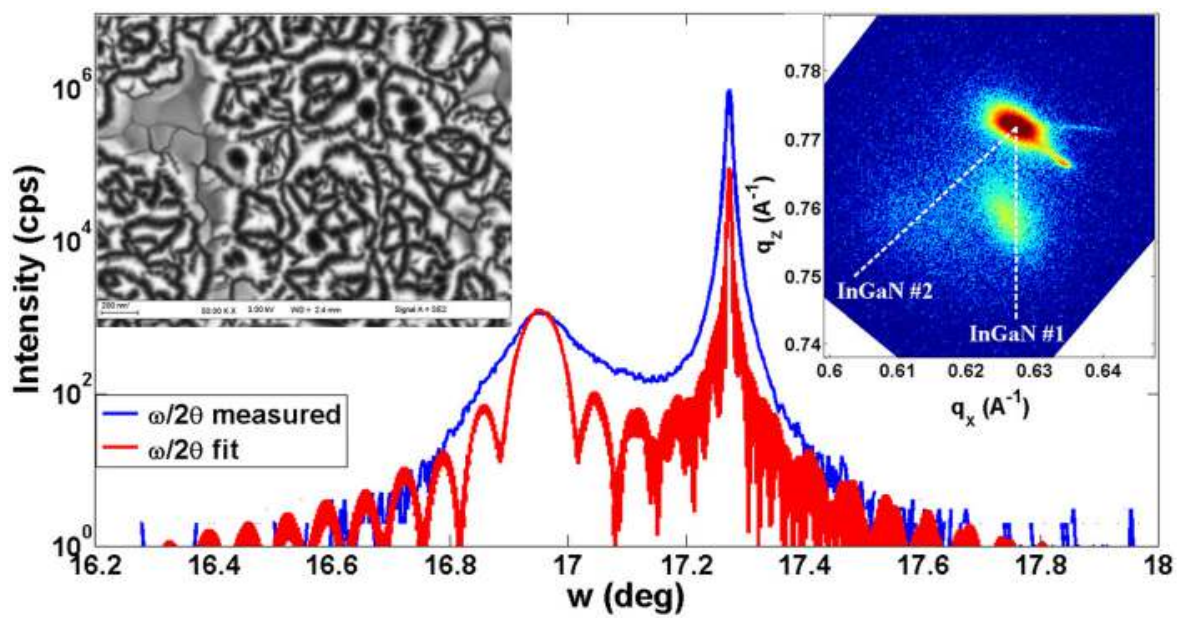

FIG. 3. XRD $2 \theta-\omega$ scans for 002reflection planes of planar InGaN. The left and right insets show the SEM image of the surface and RSM of planar InGaN, respectively. simulation, the average indium incorporation in the $\mathrm{InGaN}$ layer was found to be around $12 \%$. The RSM of the control sample which is also shown in the latter figure reveals two different InGaN diffraction spots. One is aligned exactly with the $\mathrm{GaN}$ peak ( $\mathrm{InGaN \# 1)}$ and corresponds to the pseudomorphically strained InGaN with $12 \%$ In content. Another weak intensity peak ( $\mathrm{InGaN \# 2)}$ is completely off aligned from the $\mathrm{GaN}$ peak and corresponds to the relaxed InGaN layers with In content averaging around 23\%. The appearance of the double diffraction peaks is due to phase separation and is a normal feature of thick InGaN samples as previously reported by several authors. ${ }^{22-24}$

Fig. 4 shows different magnifications of HAADF STEM images of InGaN nanorods. The very good uniformity of the hexagonal pyramid shaped nanorods, the clear contrast between the $20 \mathrm{~nm} \mathrm{GaN}$ regrowth layer and $150 \mathrm{~nm} \mathrm{InGaN}$, and the absence of threading dislocation emerging from the interfaces in the nanorods are all apparent. Fig. 4(e) shows $2 \theta-\omega$ map of diffracted intensity collected simultaneously from the nanorods and planar $\mathrm{InGaN}$ at the (00.4) reflection using synchrotron-based XRD. The signal width along the $\omega$ axis corresponds to mosaic spread, and the width of the nanorods signal is due to the variety of orientations among the nanorods. These results show clearly that the InGaN nanorod is single crystal with slightly misoriented grains, one being housed inside the $\mathrm{SiO}_{2}$ mask and the other emerging out from the mask with hexagonal pyramid shape. According to data of Fig. 4(e), the In content is slightly higher in the nanorods (around 22\%) than in the field (around 21\%).

The high-resolution TEM image of one nanorod shown in Fig. 4(d) clearly evidences its defect free growth. According to localized EDX measurements recorded with a
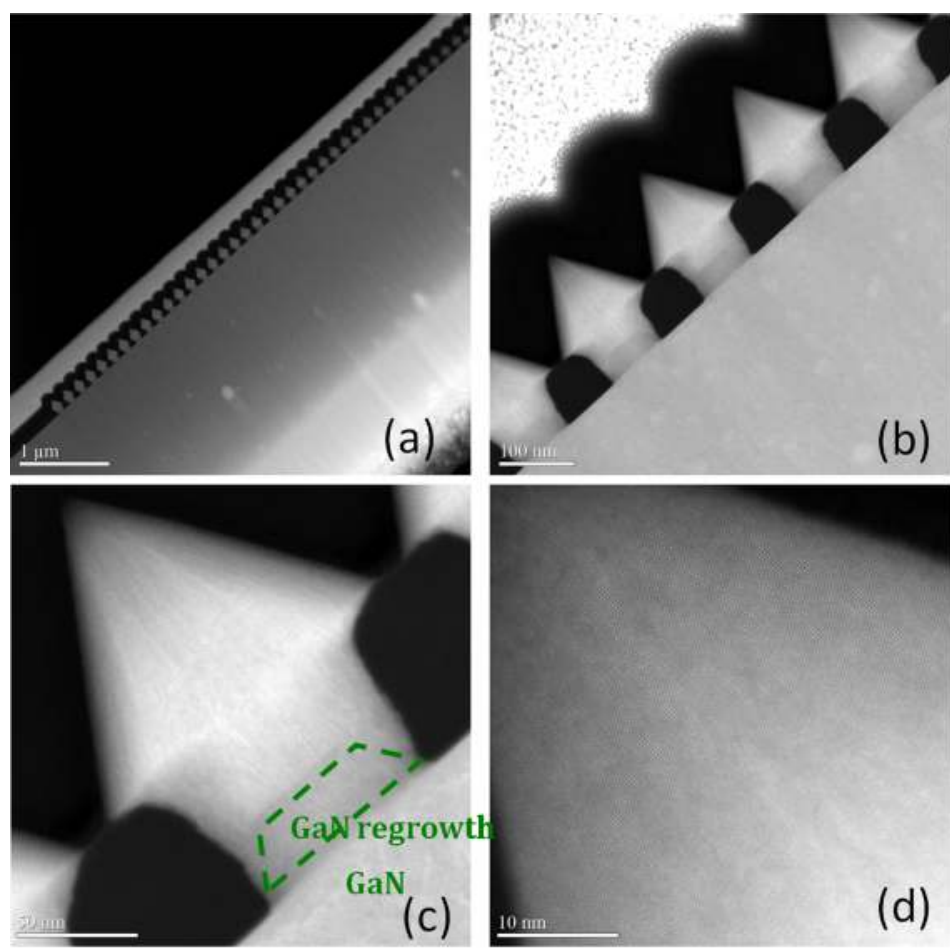

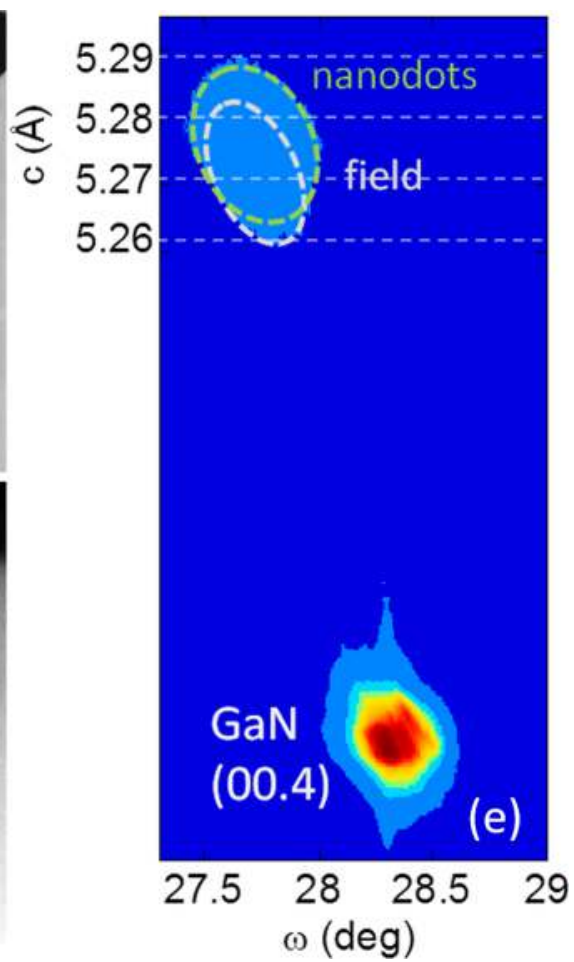

FIG. 4. (a)-(d) Different magnifications of HAADF cross sectional STEM images of InGaN nanorods, (e) $2 \theta-\omega$ map of diffracted intensity collected simultaneously from the nanorods and planar InGaN at the (00.4) reflection using synchrotron-based XRD. 

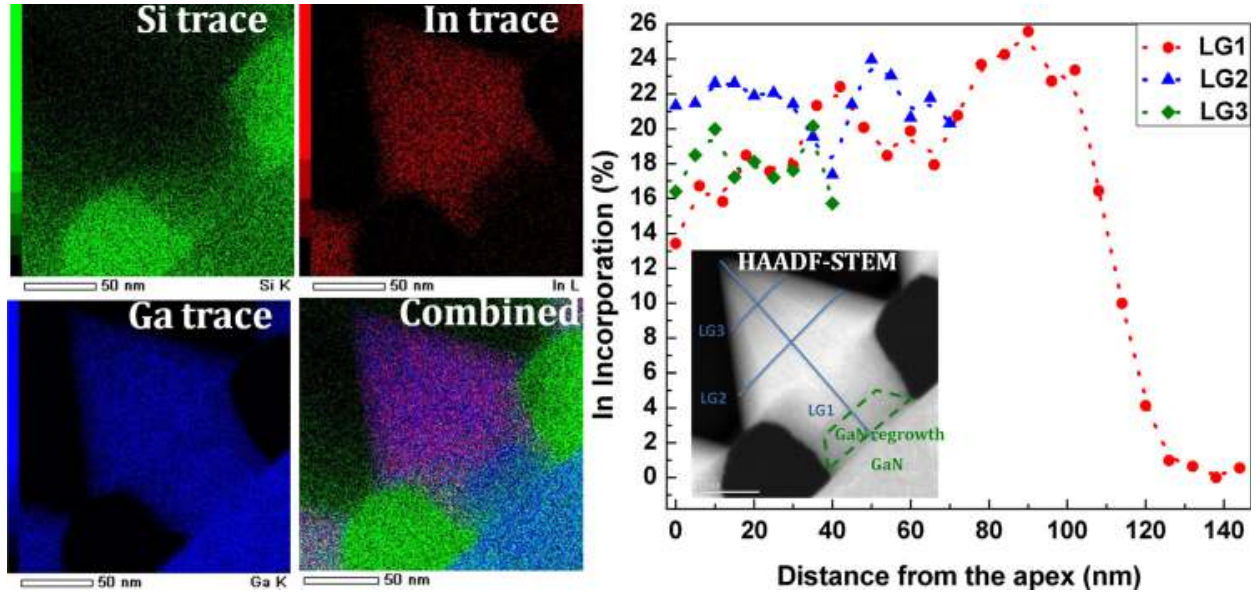

$5 \mathrm{~nm}$ pitch (see Fig. 5), the nanorod exhibits rather good In content homogeneity along axes perpendicular to the c-axis (LG2 and LG3 lines with around 22\% and $18 \%$ of In content, respectively), with a corresponding gradient of In content along the c-axis (LG1 line, along which the In content varies from $16 \%$ (apex of the nanorod) to $25 \%$ (near the InGaN / $\mathrm{GaN}$ interface)). These EDX profiles are in a very good agreement with data deduced from submicron-beam XRD analysis and confirm that there is a sharp growth interface between GaN and InGaN layers. The regrowth of GaN and InGaN layers does not emerge from the $\mathrm{SiO}_{2}$ patterns confirming that the growth is epitaxial with perfect selectivity.

Fig. 6 shows both the STEM image of an InGaN nanostripe and CCD image of the diffracted intensity collected at the (00.4) reflection using synchrotron-based submicronbeam XRD. Fig. 6(a) clearly shows a contrast difference between the GaN and InGaN layers, the latter having extra rplane triangular facets on the sidewalls when compared to InGaN nanorods. Along the c-axis of the InGaN layer, there are two regions with large contrast difference. The first region called InGaN1 has an In incorporation of around 13\% and the second one, called InGaN2, an In content around $20 \%$ (both evaluated using localized EDX measurements). The InGaN1 sublayer starts to grow along the c-axis with semipolar r-plane facets and forms the core of the nanostripe. Then the InGaN2 sublayer grows on these semipolar r-plane surfaces. The latter growth, on semipolar r-plane surfaces, stops the growth of $\mathrm{InGaN}$ along the c-axis and forms an
InGaN vein like with an In incorporation of around $6.5 \%$. This figure also shows the boundary region with a slight misorientation between InGaN1 and InGaN2 sublayers. The growth on the semipolar facets is of importance and has advantages over the conventional c-axis growth since it allows reduction of the piezoelectric polarization effects which can play a detrimental role in the performance of solar cells based on InGaN material. The synchrotron submicronbeam XRD analysis (Fig. 6(b)) confirms the STEM results. The warmer colors correspond to higher intensity. Signals from five distinct grains are present: one from the GaN substrate, one from the GaN regrowth, one from the InGaN1 region, and two from the $\mathrm{InGaN} 2$ region. Indium content, calculated from diffraction data using the method of Schuster et ll $^{26}$ is $13 \%$ and $20 \%$ for InGaN1 and InGaN2, respectively. These results are in very good agreement with data deduced from EDX measurements. Since the In incorporation rate is higher for growth directions along an axis perpendicular to r-planes than along the c-axis, such a difference of In content between the core (InGaN1) and the sidewalls (InGaN2) of the nanostripe is expected.

\section{B. Optical characterizations}

Fig. 7 shows the low temperature $(77 \mathrm{~K})$ electron beam energy dependence of CL spectra in planar InGaN, and single InGaN nanostripe and nanorod, respectively. At low beam energy $(3 \mathrm{keV})$, the electron beam energy corresponds
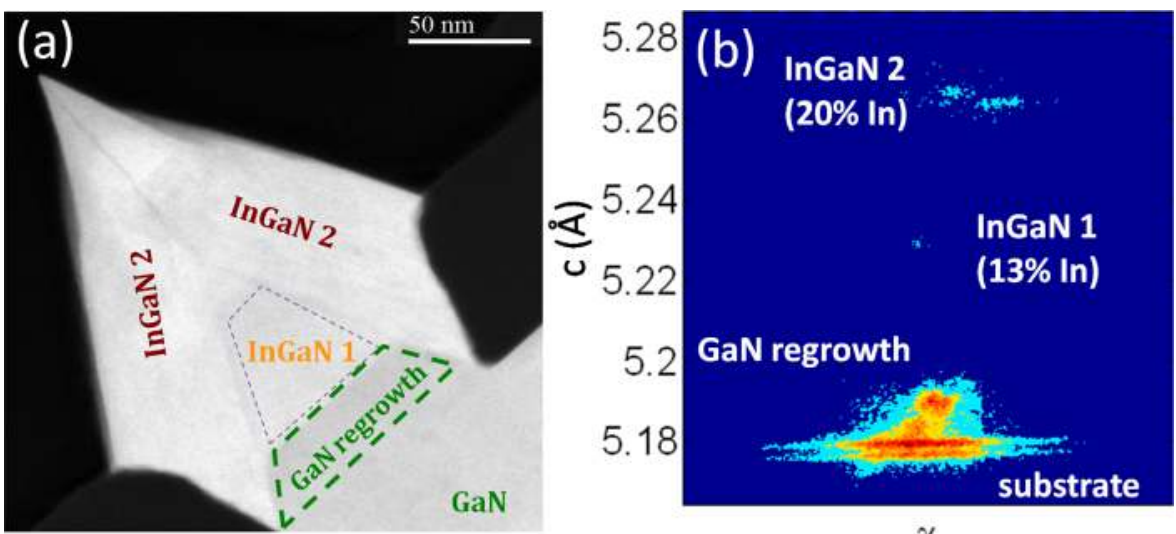

FIG. 6. (a) Cross sectional STEM images and (b) diffracted intensity collected at the (00.4) reflection using synchrotron-based submicron-beam $\mathrm{XRD}^{25}$ of an InGaN nanostripe. The angle $\chi$ corresponds to the orientation of the (00.1) planes around the length of the nanostripe. 


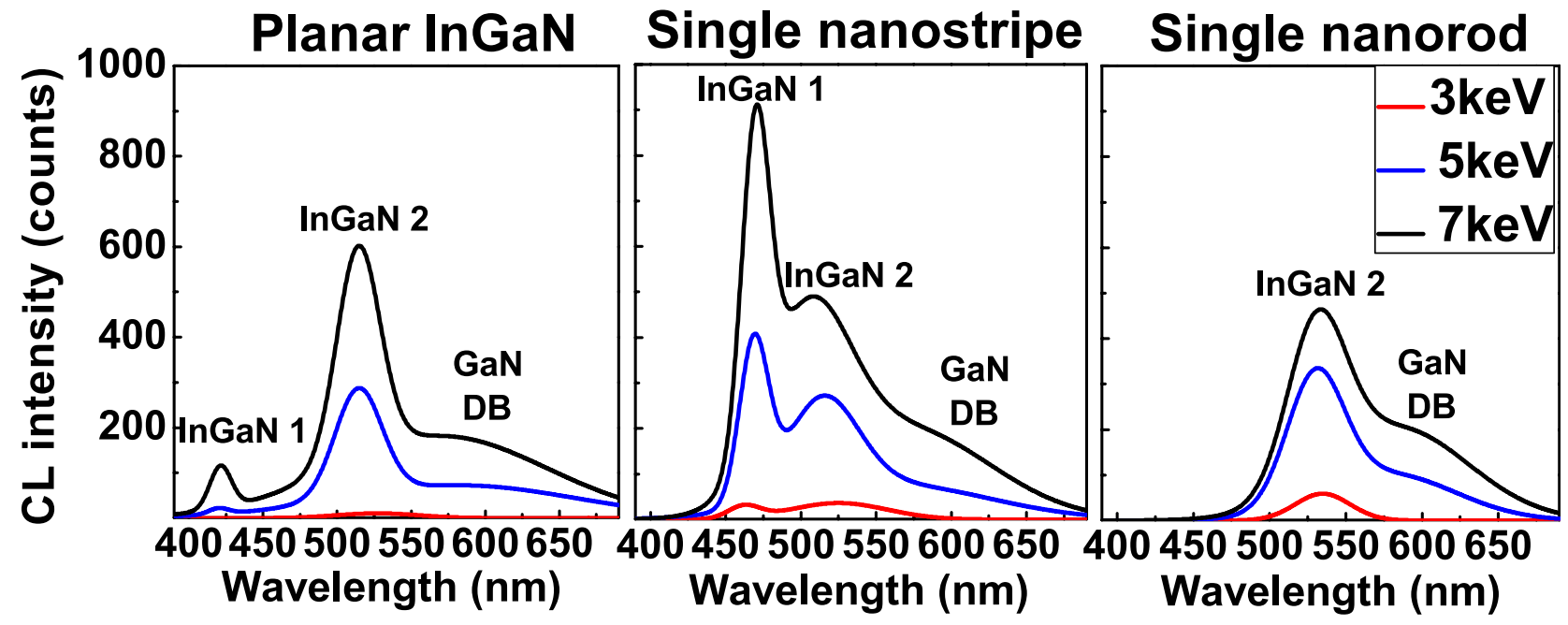

FIG. 7. $77 \mathrm{~K}$, electron beam energy dependence of CL spectra in planar InGaN, and single InGaN nanostripe and nanorod. DB stands for defect band.

to a depth of maximum energy loss of $30 \mathrm{~nm}$, and thus, the spectra reveal mainly the luminescence of the InGaN layer. In contrast to the single luminescence peak centered around $535 \mathrm{~nm}$ obtained for the InGaN nanorod, both the InGaN nanostripe and planar InGaN exhibit two luminescence bands, centered at $464 \mathrm{~nm}$ and $525 \mathrm{~nm}$ for the nanostripe, and $420 \mathrm{~nm}$ and $520 \mathrm{~nm}$ for the planar InGaN. For the whole set of structures, we can also notice a broad luminescence band centered around $590 \mathrm{~nm}$ which is attributed to the GaN defect band. In the planar InGaN, the presence of the two luminescence bands can be attributed to the presence of strained InGaN1 and relaxed InGaN2 sublayers, ${ }^{14,15}$ whereas the two luminescence bands observed in the nanostripe might be attributed to the fully relaxed InGaN1 and InGaN2 regions as shown in Fig. 6. Indium composition in the different structures is determined according to the work of Orsal et $a .^{27}$ taking into account both the relaxation rate of the layer and the associated bandgap bowing parameter. Using data of Fig. 7, the In content of the strained and fully relaxed sublayers of planar InGaN are $12 \%$ and $21 \%$, respectively. These results are in good agreement with data deduced from high-resolution XRD $2 \theta-\omega$ scan and RSM of the control sample (see Fig. 3) and discussed in the previous section. In the nanostripe, according to data of Fig. 7, the In composition of the two relaxed layers are $14 \%$ and $21 \%$, whereas in the nanorod only one relaxed InGaN phase with $22 \%$ of In is revealed. This is expected since, as shown in Fig. 4, unlike the nanostripe which exhibits a structure with a core (InGaN1) and sidewalls (InGaN2), the nanorod is single crystal (InGaN2) with growth directions along axes perpendicular to r-planes. These results are in very good agreement with data deduced from both EDX and synchrotron submicron-beam XRD measurements presented in Section III A. For the same growth condition, the In incorporation in the nanorods is a little larger than in the nanostripes and almost twice as high as in planar InGaN. Increasing the electron beam energy leads to luminescence coming from deeper regions of the InGaN layer. In contrast to planar InGaN and nanostripe, the nanorod luminescence intensity tends (see Fig. 7) to saturate with increasing electron beam energy. This indicates that the interaction plume becomes larger than the nanostructure.

Fig. 8 shows both InGaN planar, nanostripe, and nanorod, electron beam energy dependence of the intensity and FWHM of the luminescence peak related to the highest In
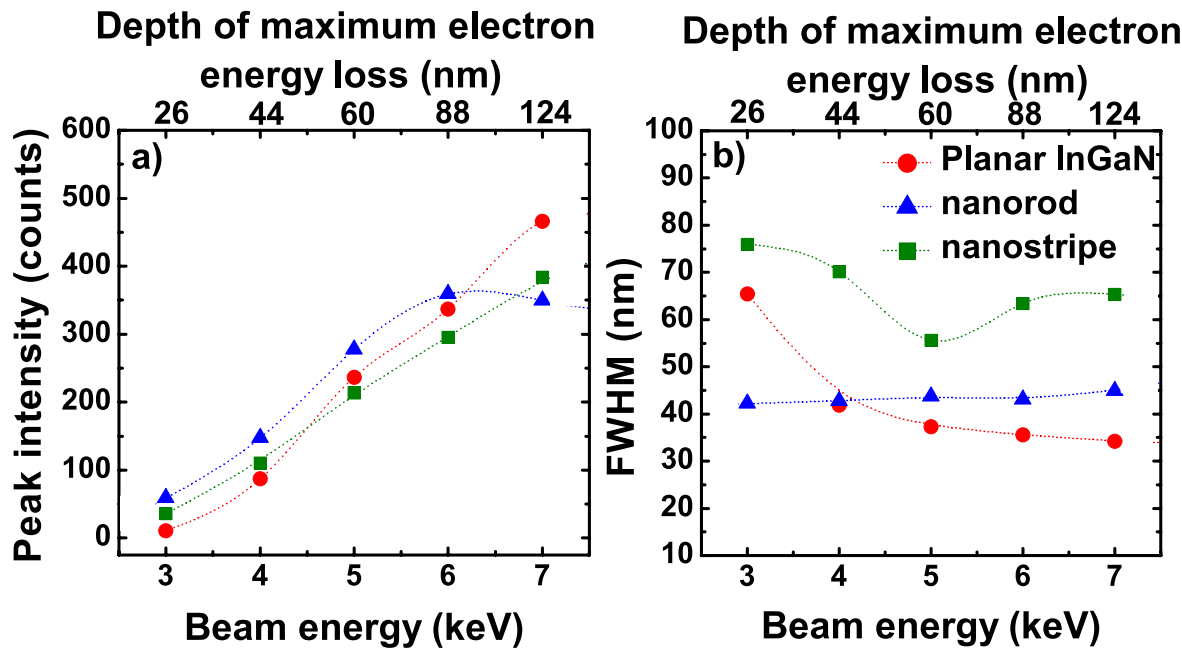

FIG. 8. InGaN planar, nanostripe, and nanorod, electron beam energy dependence of the intensity and FWHM of the luminescence peak related to the highest In content InGaN2 layer. 
content InGaN2 layer. The nanorod exhibits the highest luminescence intensity, and, at low electron energy beam, the lowest luminescence peak FWHM. This could indicate that the InGaN alloy in the nanorod possesses a lower structural disorder and defect density, with the highest In incorporation, when compared to planar InGaN and nanostripe.

\section{CONCLUSION}

In conclusion, we have demonstrated the growth of single phase, almost dislocation free, $150 \mathrm{~nm}$ thick, and In-rich (up to $22 \%$ ) InGaN nanorods and nano stripes on $\mathrm{SiO}_{2}$ patterned c-oriented $\mathrm{GaN}$ templates. When compared to other work, ${ }^{18,19}$ the patterning process of the substrate used in this study seems to greatly improve the structural quality of the nanostructures by allowing better wafer surface quality for nucleation. These nanostructures mitigate the propagation and generation of dislocations, as well as strain-related degradations and In clustering observed in planar InGaN. The NSAG of dense, In rich, and thick InGaN nanostructures arrays is a very promising approach for the realization of complete p-i-n structures with high quality thick InGaN nanostructures embedded on it. It allows high In incorporation in thick layer, circumvention of the intrinsic problem of defects in planar InGaN, and thus, may provide significant enhancement on the conversion efficiency of InGaN-based solar cells.

\section{ACKNOWLEDGMENTS}

This work was supported by the French National Research Agency (ANR), under the GANEX LABEX program and NOVAGAINS project (ANR-12-PRGE-001402), and CNRS INCEPT PEPS project. This research used resources of the Advanced Photon Source, a U.S. Department of Energy (DOE) Office of Science User Facility operated for the DOE Office of Science by Argonne National Laboratory under Contract No. DE-AC02$06 \mathrm{CH} 11357$.

${ }^{1}$ O. Jani, I. Ferguson, C. Honsberg, and S. Kurtz, Appl. Phys. Lett. 91,132117 (2007).

${ }^{2}$ C. Neufeld, N. Toledo, S. Cruz, M. Iza, S. Denbaars, and U. Mishra, Appl. Phys. Lett. 93, 143502 (2008).

${ }^{3}$ R. Dahal, B. Pantha, J. Li, J. Y. Lin, and H. X. Jiang, Appl. Phys. Lett. 94, 063505 (2009).

${ }^{4}$ R. Dahal, J. Li, K. Aryal, J. Y. Lin, and H. X. Jiang, Appl. Phys. Lett. 97, 073115 (2010).
${ }^{5}$ E. Matioli, C. Neufeld, M. Iza, S. C. Cruz, A. A. Al-Heji, X. Chen, R. M. Farrell, S. Keller, S. Denbaars, U. Mishra, S. Nakamura, J. Speck, and C. Weisbuch, Appl. Phys. Lett. 98, 021102 (2011).

${ }^{6} \mathrm{~S}$. Nakamura, S. Pearton, and G. Fasol, The Blue Laser Diode: The Complete Story, Physics and astronomy online library (Springer, 2000).

${ }^{7}$ X. Chen, K. D. Matthews, D. Hao, W. J. Schaff, and L. F. Eastman, Phys. Status Solidi A 205, 1103-1105 (2008).

${ }^{8}$ R. M. Farrell, C. J. Neufeld, S. C. Cruz, J. R. Lang, M. Iza, S. Keller, S. Nakamura, S. P. DenBaars, U. K. Mishra, and J. S. Speck, Appl. Phys. Lett. 98, 201107 (2011).

${ }^{9}$ M. Rao, D. Kim, and S. Mahajam, Appl. Phys. Lett. 85, 1961 (2004).

${ }^{10}$ S. Pereira, M. R. Correia, E. Pereira, K. P. O’Donnell, C. Trager-Cowan, F. Sweeney, and E. Alves, Phys. Rev. B 64, 205311 (2001).

${ }^{11}$ D. Fuhrmann, C. Netzel, U. Rossow, A. Hangleiter, G. Ade, and P. Hinze, Appl. Phys. Lett. 88, 071105 (2006).

${ }^{12}$ N. G. Young, R. M. Farrell, Y. L. Hu, Y. Terao, M. Iza, S. Keller, S. P. DenBaars, S. Nakamura, and J. S. Speck, Appl. Phys. Lett. 103, 173903 (2013).

${ }^{13}$ K. Pantzas, Y. El Gmili, J. Dickerson, S. Gautier, L. Largeau, O. Mauguin, G. Patriarche, S. Suresh, T. Moudakir, C. Bishop, A. Ahaitouf, T. Rivera, C. Tanguy, P. L. Voss, and A. Ougazzaden, J. Cryst. Growth 370, 57 (2013).

${ }^{14}$ Y. El Gmili, G. Orsal, K. Pantzas, T. Moudakir, S. Sundaram, G. Patriarche, A. Ahaitouf, J. P. Salvestrini, and A. Ougazzaden, Acta Mater. 61(17), 6587 (2013).

${ }^{15}$ Y. El Gmili, G. Orsal, K. Pantzas, A. Ahaitouf, T. Moudakir, S. Gautier, G. Patriarche, D. Troadec, J. P. Salvestrini, and A. Ougazzaden, Opt. Mater. Express 3(8), 1111 (2013).

${ }^{16}$ W. H. Goh, G. Patriarche, P. L. Bonanno, S. Gautier, T. Moudakir, M. Abid, G. Orsal, A. A. Sirenko, Z. Cai, A. Martinez, A. Ramdane, L. Le Gratiet, A. Soltani, and A. Ougazzaden, J. Cryst. Growth 315, 160 (2011).

${ }^{17}$ T. Kuykendall, P. Ulrich, S. Aloni, and P. D. Yang, Nature Mater. 6, 951 (2007).

${ }^{18}$ Y. Wang, K. Zang, S. Chua, M. S. Sander, S. Tripathy, and G. Fonstad, J. Phys. Chem. B 110, 11081 (2006).

${ }^{19}$ J. Song, B. Leung, Y. Zhang, and J. Han, Nanotechnology 25, 225602 (2014).

${ }^{20}$ S. Gautier, C. Sartel, S. Ould-Saad, J. Martin, A. Sirenko, and A. Ougazzaden, J. Cryst. Growth 298, 428 (2007).

${ }^{21}$ K. Pantzas, G. Patriarche, D. Troadec, S. Gautier, T. Moudakir, S. Suresh, L. Largeau, O. Mauguin, P. L. Voss, and A. Ougazzaden, Nanotechnology 23, 455707 (2012).

${ }^{22}$ Z. Liliental Weber, K. M. Yu, M. Hawkridge, S. Bedair, A. E. Berman, A. Emara, J. Domagala, and J. Bak Misiuk, Phys. Status Solidi C 6, S433 (2009).

${ }^{23}$ H. Wang, D. Jiang, U. Jahn, J. Zhu, D. G. Zhao, Z. Liu, S. Zhang, and H. Yang, Thin Solid Films 518, 5028 (2010).

${ }^{24}$ K. Pantzas, G. Patriarche, G. Orsal, S. Gautier, T. Moudakir, M. Abid, V. Gorge, Z. Djebbour, P. L. Voss, and A. Ougazzaden, Phys. Status Solidi A 209, 25 (2012).

${ }^{25}$ P. L. Bonanno, S. Gautier, A. A. Sirenko, A. Kazimirov, Z.-H. Cai, W. H. Goh, J. Martin, A. Martinez, T. Moudakir, N. Maloufi, M. B. Assouar, A. Ramdane, L. Le Gratiet, and A. Ougazzaden, Nucl. Instrum. Meth. Phys. Res. B 268(34), 320-324 (2010).

${ }^{26}$ M. Schuster, P. O. Gervais, B. Jobst, W. Hosler, R. Averbeck, H. Riechert, A. Iberl, and R. Stommer, J. Phys. D: Appl. Phys. 32, A56 (1999).

${ }^{27}$ G. Orsal, Y. El Gmili, N. Fressengeas, J. Streque, R. Djerboub, T. Moudakir, S. Sundaram, A. Ougazzaden, and J. P. Salvestrini, Opt. Mater. Express 4(5), 1030 (2014). 